\title{
3 Research Square

\section{A New Perspective of Urban-rural Differences: the Impact of Supply and Demand on Healthcare Services for the Older Adults: a Case Study of Shaanxi Province}

Chi Zhang ( $\nabla$ zc499167736@stu.xjtu.edu.cn )

Xi'an Jiaotong University School of Public Policy and Administration https://orcid.org/0000-0003$1431-7722$

Qing Niu

Xi'an Jiaotong University

Sifeng Zhang

Xi'an Jiaotong University

Research

Keywords: older adults, healthcare services, multiple regression, urban-rural difference

Posted Date: June 25th, 2021

DOl: https://doi.org/10.21203/rs.3.rs-634282/v1

License: (c) (1) This work is licensed under a Creative Commons Attribution 4.0 International License.

Read Full License 


\section{Abstract}

Background: With the rapidly aging of Chinese society and the change of Chinese residents' disease spectrum, the older adults utilization of the healthcare services surges as well. Studies on factors that potentially influence the utilization of healthcare services for the older adults becomes increasing important, which could benefit improving the service effect and the quality of life of the older adults in later life. This article compares and analyzes the differences in the using of healthcare services by the older adults in urban and rural areas based on the supply and demand of healthcare services for the older adults and analyzes the reasons for potential differences.

Methods: Using data from a survey conducted in three cities in Shaanxi Province in 2019. All authors participated in the questionnaire survey. We obtained a total of 948 questionnaires. Multivariate regression model and Oaxaca-Blinder decomposition model are used to analyze the difference between the supply and demand of medical services for the older adults in urban and rural areas.

Results: The results find that age, household register, living activities of daily living ( $A D L),(P<0.01)$ and healthcare treatment insurance significantly impact the older adults use of healthcare services.

Meanwhile, factors from the supply and demand factors have a significant correlation with the utilization of services for the older adults, including the healthcare service quality $(P<0.01)$, the diversity of service content $(P<0.01)$, the rationality of service charge $(P<0.01)$, service satisfaction $(P<0.01)$, family support $(P<0.1)$ level and the main illness $(P<0.05)$. Moreover, the results show a significant difference in the use of healthcare services for the older adults between urban and rural areas. Specifically, in urban areas, the influences of service quality, the diversity of service content and the rationality of service from the supply have a significant correlation with the utilization of services for the older adults. The service satisfaction, service demand and family support in the demand factors have a significant correlation with the utilization of services for the older adults. In comparisons, for the older adults in rural areas, the diversity of service content from the supply factors as well as economic level and main illness from the demand factors have a significant correlation with the utilization of services for the older adults.

Conclusions: From the perspective of supply and demand, this paper constructs an analytical framework of the determinants of healthcare services for the older adults from a new perspective. Based on the analysis framework and from the perspective of supply and demand of healthcare services utilization, the differences between urban and rural areas in the utilization of medical care for the older adults and the influencing factors are studied. It provides a new research perspective to explore the influencing factors of healthcare services utilization for the older adults. Supply factors and demand factors have a significant correlation with the utilization of healthcare services for the older adults. There are also significant differences in the factors influencing the utilization of health services by urban and rural older adults. When strengthening and improving the supply of healthcare services for the older adults, the previous thinking of "top-down" and "service-centered" should be changed, and gradually transformed into "bottom-up" and "demand-centered". 


\section{Introduction}

\section{Background}

In recent years, with the accelerating aging population in China, the utilization of healthcare services for the older adults has been paid more attention by the government and the public [1]. At the same time, the disease spectrum's changes in China drive the older adults increasing demand for healthcare services [2]. Although China older adults healthcare services experienced a rapid development under the guidance of the government's policies and the market promotions, the utilization level of healthcare services for the older adults is still relatively low, which leads to the dilemma of "supply " and "demand "[3]. To better solve the dilemma of supply and demand imbalance, improve the effect of healthcare services, and promote the healthcare and sustainable development of healthcare services, the research on the factors influencing the utilization of healthcare services for the older adults will be of great value. At the same time, due to the dual economic system of urban and rural areas and the inverted "pyramid" configuration of healthcare resources, the utilization of healthcare services between urban and rural residents have significant difference, which is getting larger day by day [4].

The reform of household registration and the integration of the healthcare insurance system for urban and rural residents provides a channel for rural residents to enter into urban areas freely [5], which is conducive to improving the accessibility of healthcare services [6]. Studies have found that even in rural areas where purchasing power is strong, the use of healthcare services is still much lower than in cities, and it is pervasive in almost every country in the world [7]. Therefore, under this situation, it is of great practical significance to reconsider and study the utilization of healthcare services for urban and rural residents.

At present, the research on the utilization of healthcare services for the older adults is mainly focused on the overall community older adults healthcare services, and there is a lack of discussion on the mechanism and influencing factors of the utilization of healthcare services for the older adults. Along with the deepening of aging in China, the service demands of the older adults in China have been transformed and upgraded, and the older adults have the greatest demand for healthcare services among all kinds of older adults needs. Therefore, it is necessary to discuss the influencing factors of health service utilization of the older adults in urban and rural areas and the inequality mechanism behind. Most of the studies on the influencing factors of healthcare service utilization of the older adults discuss the demand-side factors such as economic level, health status, and family support for inequality, and lack the discussion of supply factors such as service supply and service price. Therefore, it is necessary to explore the inequality of healthcare service utilization among the older adults in urban and rural areas and the influencing factors behind it from both the supply and demand factors.

Analysis Framework

The Anderson Model of Health Care Delivery is the most widely used model in academia to measure the influences on health care delivery. The Anderson Model classifies the influences on individual health care 
utilization into Predisposing characteristics, enabling resources, and Needs [8]. This article analyzes the factors influencing the utilization of medical services from the supply and demand perspectives, so it is necessary to expand the Anderson model from the supply and demand perspectives of healthcare services for the older adults to form a model of supply and demand for healthcare services for the older adults. firstly, the predisposing characteristics in the Anderson model are used as the control variables in the article, such as age, marriage, education and other characteristics [9]. Previous research shows: Personal self-assessment of health and gender will have a significant impact on the utilization of healthcare services the utilization of healthcare services for the older adults will be affected by the basic healthcare insurance (Health Insurance) [10]. The increase in the older adults will promote the probability of healthcare service utilization, and the aging rate will significantly affect the utilization of healthcare services for the older adults [11]. Education level and income of the older adults will influence the utilization of healthcare services for the older adults [12]. Marital status and self-care ability will also affect the use of healthcare services for the older adults[13]. Enabling resources in the Anderson model are used as supply factors in the article, including community-provided healthcare service resources for the older adults, healthcare Accessibility and others. finally, Needs in the Anderson model are used as demand factors in the article, the degree of subjective needs of the older adults for healthcare service resources, health status, and family support are taken as demand factors. Thus, using the original Anderson model, Supply and demand model of healthcare services utilization for the older adults in urban and rural areas was constructed.

Finally, this study constructed an analytical framework for the impact of supply and demand on older adults healthcare services, as shown in Figure 1. An additional figure file shows this in more detail [see Additional file 1].

H1: Supply factors, including: healthcare quality, accessibility, diversity, rationality have a significant correlation with the utilization of services for the older adults

From the supply factors, healthcare services supply is an important prerequisite for the utilization of healthcare services for the older adults. On the basis of adequate service supply, some scholars point out that healthcare services quality[14], healthcare services accessibility affect healthcare service utilization affects healthcare service utilization [15], healthcare services charges affect frequency of use of medical services for the older adults [16].The greater the diversity of community-supplied medical services, the higher the utilization of medical services for the older adults [17].Quality of healthcare services are the deciding factor of healthcare utilization among older adults [18].

H2: Demand factors, including: healthcare satisfaction, need, economic level, family support, major illness have a significant correlation with the utilization of services for the older adults.

From the demand factors, Different models of healthcare affects the probability of healthcare service utilization for the older adults [19]. Healthcare reform plan and healthcare system affect the utilization of healthcare services for the older adults [20]. The type of healthcare services, the accessibility of healthcare services, and the price of healthcare services will all affect the use of healthcare services by 
the older adults [21]. the demand for healthcare services is the direct driving force for the older adults to use healthcare services [22]. At the same time, this potential demand is transformed into actual demand, which is directly affected by the economic level, family support, illness of the older adults and other factors, as well as the feedback of service satisfaction [23]. Relevant studies have shown that the higher the service satisfaction [24], the better the economic level [25], and the more likely the older adults are to use healthcare services in the case of severe illness [26]. The lower the income of the older adults, the less healthcare services will be used [27]. The higher the drug usage rate, the higher the utilization rate of healthcare services [28-29]. The research of Yonatan (2020) shows that providing psychedelic therapy is economically beneficial to the healthcare system, reducing the utilization and cost of healthcare services [30]. Chronic diseases and major diseases will increase the use of healthcare services by the older adults [31]. Healthcare services satisfaction affects healthcare service utilization [32]. Family support, including financial support, partner support, and children's support will affect the use of healthcare services for the older adults [33-34].

H3: There are obviously differences in the utilization of healthcare services for the older adults between urban and rural areas.

Due to the urban-rural dual structure in China, there are significant differences between urban and rural areas in the supply of healthcare services and the economic income of the older adults [35], and there are also significant differences in the influence of supply-side and demand factors on the utilization of healthcare services for the older adults in urban and rural areas [36]. In general, urban older adults are more inclined to use healthcare services due to their higher economic level, education level, and better healthcare insurance [37]. Tendency factors and demand factors will narrow the gap between urban and rural areas in the use of healthcare services, and rural older adults who are supported by their children are more willing to use healthcare services [38]. Ming-Chung (2018) showed that there is no significant urbanrural difference in the frequency of emergency department utilization for the older adults, but there are significant differences in health services [39]. There are also significant differences in the types and influencing factors of healthcare service utilization between urban and rural older adults [40].

\section{Methods}

\section{Ethics approval and consent to participate}

This study is approved by the Department of Social Sciences of the Ministry of Education, PRC and the Medical Ethics Committee of Health Science Center of Xi 'an Jiaotong University (Approval Number 2016416). The questionnaire is anonymous, and participation in the questionnaire is considered as informed consent.

\section{Data Sources}

The data for the study come from field surveys. The survey is conducted in Shaanxi Province from July to August 2019 by stratified random sampling method. The first stage stratification is based on cities, the 
second stage stratification is based on counties, the third stage stratification is based on villages, and the fourth stage stratification sampling is based on older adults. Three cities, Hanzhong, Baoji and Yan 'an, are selected. These three cities are characterized by high aging degree and rapid development of geriatric medical and health services. A total of 948 valid questionnaires are obtained in this survey. This paper selects the data of the demand and supply of medical services for the older adults, and finally obtains 670 valid samples.

\section{Variable Selection}

Utilization of healthcare services is defined as the number of older adults who have used the healthcare services provided by the community. It is measured by asking "the content of healthcare services provided by the community you have used (multiple choice)", including healthcare management, on-site diagnosis, and community healthcare. Accompanying healthcare treatment, rehabilitation care, and smart older adults care services. A value of 1 means that the older adults have used the service, and a value of 0 means that the older adults have not used the service. The score for the use of each service by adding up, we get the healthcare service utilization variable, with a value range of $0-6$. The higher the score, the more the older adults use healthcare services.

According to the analysis framework of the research, the independent variables mainly include two categories. The first category is the supply side, which is mainly measured through service quality, service accessibility, service supply diversity, and service charges. Service quality refers to the level of the older adults perception of the quality of healthcare services, ranging from 0 to 5 . The higher the score, the better the quality of service; the accessibility of services refers to the convenience of the older adults to the nearest clinic/healthcare service center. The Likert scale is measured with a value of $1 \sim 5$; the service provision mainly includes healthcare management, on-site diagnosis, community healthcare, accompanying healthcare treatment, rehabilitation care, and smart older adults care services, through inquiring about "healthcare services provided by the community" Content (multiple choice)" is measured, 1 means the community provides the service, 0 means the community does not provide it, and the scores of the various service contents provided are added up to obtain the service supply diversity variable; service charges refer to the older adults Consider the level of healthcare service charges, the value is 1 5. The second category is the demand side, which is mainly measured by service satisfaction, service needs, economic level, family support, and major illnesses. Service satisfaction refers to the feedback impact of service effects, which refers to the degree of satisfaction of the older adults with the healthcare and nursing services provided by the community; service needs include healthcare management, on-site diagnosis, healthcare in the community, accompanying healthcare treatment, rehabilitation care, and smart older adults healthcare services. 1 means the older adults have a need for this service. 0 means that the older adults do not need it. Finally, the scores are added to get the service demand variable. The higher the score, the greater the need; economic level refers to the total annual income of the older adults in the previous year; family support refers to The emotional support of children and other family members to the older adults is expressed by whether the older adults and their relatives communicate frequently; 
the main illnesses refer to the physical healthcare of the older adults, including major illness requiring hospitalization, chronic diseases, mental diseases, common diseases or frequently-occurring diseases.

According to previous research literature, the control variables used in the analysis include age, gender, education, marriage, household registration, work before retirement, activities of daily living in life, mental state, and healthcare insurance. Among them, the activities of daily living for daily life is a composite of the interviewees' scores on the 6 indicators of eating, dressing, getting in and out of bed, going to the toilet, walking indoors, and bathing, with a value of $0 \sim 6$. The worse the activities of daily living. The setting and description of the variables are shown in Table 1.

Table 1. Description of variables. 


\section{Variable \\ Classification}

Dependent variable

Control variable
Variable Name

Healthcare services utilization

\begin{tabular}{ll} 
Age & Over 60 years old \\
\hline Gender & Male=0 Female $=1$ \\
\hline Education & Primary school=1 \\
& Junior high school=2 \\
& High school=3 \\
& Junior college=4 \\
& University=5 \\
& Married=1 Unmarried=2 \\
Marriage & City=1 Countryside =2 \\
$\begin{array}{l}\text { Registered } \\
\text { permanent } \\
\text { residence }\end{array}$ & \\
\hline
\end{tabular}

Work before

retirement

Variable Description

$0 \sim 6$

Over 60 years old

Government staff $=1$
Enterprise employees $=2$

Self-employed $=3$

Farmer $=4$

Migrant Workers $=5$

Other $=6$

Activities of daily $\quad 0 \sim 6$

living $\triangle A D L \bigotimes$

Mental state $\quad$ Very bad $=1$

Bad $=2$

Average $=3$

Better $=4$

Well $=5$

Healthcare

Resident Healthcare Insurance=1

insurance
Employee healthcare insurance $=2$

Nothing $=3$ 


\begin{tabular}{|c|c|c|}
\hline \multirow[t]{3}{*}{$\begin{array}{l}\text { Healthcare } \\
\text { Supply }\end{array}$} & Accessibility & $\begin{array}{l}\text { Very inconvenient }=1 \text {, Inconvenient }=2 \text {, Average }=3 \text {, More } \\
\text { convenient }=4 \text {, Very convenient }=5\end{array}$ \\
\hline & Diversity & $0 \sim 6$ \\
\hline & Rationality & Very low $=1$, Low $=2$, Average $=3$, High $=4$,Very high $=5$ \\
\hline $\begin{array}{l}\text { Independent } \\
\text { Variable囚 }\end{array}$ & Satisfaction & $\begin{array}{l}\text { Very dissatisfied }=1 \text {, Dissatisfied }=2 \text {, Average }=3 \text {, Satisfied } \\
=4 \text {, Very satisfied }=5\end{array}$ \\
\hline \multirow{4}{*}{$\begin{array}{l}\text { Healthcare } \\
\text { Demand }\end{array}$} & Need & $0 \sim 6$ \\
\hline & Economic level & Continuous variables \\
\hline & Family support & Very low $=1$, low $=2$, Average $=3$, High $=4$, Very high $=5$ \\
\hline & Major illness & $0 \sim 4$ \\
\hline
\end{tabular}

\section{Analysis Method}

This study uses multiple regression methods and uses Stata 15.0 for analysis. In order to analyze the direction and extent of the supply-side and demand factors influence on the utilization of healthcare services, this paper constructs 4 models. Model 1 only includes control variables, Model 2 includes both control variables and supply factors, and Model 3 includes both control variables and demand factors, Model 4 is a full model, incorporating control variables, supply-side and demand factors at the same time. The specific model is as following:

$$
\begin{gathered}
f^{1}(p)=\alpha^{1}+\beta_{1}^{1} x_{C V}+\varepsilon^{1} \\
f^{2}(p)=\alpha^{2}+\beta_{1}^{2} x_{C V}+\beta_{2}^{2} x_{S}+\varepsilon^{2} \\
f^{3}(p)=\alpha^{3}+\beta_{1}^{3} x_{C V}+\beta_{2}^{3} x_{D}+\varepsilon^{3} \\
f^{4}(p)=\alpha^{4}+\beta_{1}^{4} x_{C V}+\beta_{2}^{4} x_{S}+\beta_{3}^{4} x_{D}+\varepsilon^{4}
\end{gathered}
$$

\section{Results}

\section{Descriptive statistics of the control variables}

Table 2 showed the control variables selected in this article. Among the surveyed older adults, the mean value of age was 70 years old, the ratio of men to women was about $0.6: 1$, in terms of education, the proportion of older adults with elementary school education or below was as high as $43.28 \%$, the ratio of urban and rural population was 1.3:1, the mean value of the ability to take care of oneself in life (ADL) was 0.05 , that is, the vast majority of the older adults were not physically damaged, the type of marriage had the most older adults in marriage, accounting for The overall situation of the surveyed older adults people's use of healthcare care services was average, the percentage of those who had used healthcare 
care services was $72.24 \% .72 .24 \%$ of the respondents had used healthcare care services, but less than $3 \%$ of them had used three or more services.

Table 2. Descriptive statistics of the Control variables.

\begin{tabular}{|c|c|c|c|}
\hline Variable & Classification & Frequency & Percentage $\square \% \square$ \\
\hline \multirow[t]{2}{*}{ Age } & \multirow[t]{2}{*}{ Over 60 years old } & \multicolumn{2}{|c|}{ Mean value: 70.34} \\
\hline & & \multicolumn{2}{|c|}{ Standard deviation: 7.06} \\
\hline \multirow[t]{2}{*}{ Gender } & Male & 254 & 37.91 \\
\hline & Female & 416 & 62.89 \\
\hline \multirow[t]{5}{*}{ Education } & Primary school & 290 & 43.28 \\
\hline & Junior high school & 192 & 28.66 \\
\hline & High school & 134 & 20.00 \\
\hline & Junior college & 38 & 5.67 \\
\hline & University & 16 & 2.39 \\
\hline \multirow[t]{2}{*}{ Marriage } & Married & 481 & 71.80 \\
\hline & Unmarried & 169 & 28.20 \\
\hline \multirow[t]{2}{*}{ Registered permanent residence } & City & 381 & 56.87 \\
\hline & Countryside & 289 & 43.13 \\
\hline \multirow[t]{3}{*}{ Healthcare insurance } & Resident Health insurance & 365 & 54.48 \\
\hline & Employee health insurance & 255 & 38.06 \\
\hline & Nothing & 50 & 7.46 \\
\hline \multirow[t]{2}{*}{ Work before retirement } & Formal job & 305 & 45.55 \\
\hline & Informal job & 365 & 55.45 \\
\hline \multirow[t]{5}{*}{ Mental status } & Very bad & 5 & 0.75 \\
\hline & Bad & 44 & 6.57 \\
\hline & Average & 77 & 11.49 \\
\hline & Better & 234 & 34.92 \\
\hline & Well & 310 & 46.27 \\
\hline \multirow[t]{2}{*}{ Activities of daily living $\mathbb{A} A D L \mathbb{}$} & $0 \sim 6$ & \multicolumn{2}{|c|}{ Mean value: 0.052} \\
\hline & & \multicolumn{2}{|c|}{ Standard deviation $₫ 0.433$} \\
\hline
\end{tabular}




\section{Analysis of regression results}

Table 3 showed the results of the multiple regression analysis, with the dependent variable being healthcare services utilization, model 1 incorporating only the control variables, models 2 and 3 being the results of incorporating supply-side and demand factors, respectively, based on the control variables, and model 4 being the full model. Although there may be multicollinearity among the variables, the statistics showed that the four models did not have serious multicollinearity problems (see the notes to Table 3), which could be used as the basis for the analysis.

Table 3. Results of multiple regression analysis on the utilization of healthcare services for the older adults. 
Variable

Variable

Model 1

Model 2

पSupply!
Model 3

aDemand $]$

Model 4

aDemand-

Supply[

\begin{tabular}{lllll} 
Age & $\begin{array}{l}* .008(0.011) \\
\star\end{array}$ & $\begin{array}{l}0.013(0.009) \\
\star \star \star\end{array}$ & $0.008(0.006) *$ & $\begin{array}{l}0.013(0.010) \\
\star \star \star\end{array}$ \\
\hline Gender & $-0.019(0.008)$ & $0.025(0.012)$ & $-0.056(0.014)$ & $-0.001(0.002)$ \\
\hline Education & $\begin{array}{l}0.070(0.0011) \\
*\end{array}$ & $0.004(0.003)$ & $0.063(0.017) *$ & $0.007(0.006)$
\end{tabular}

Marriage

Married

0.038(0.014)

$0.238(0.016)$

0.045(0.011)

0.196(0.018)

Unmarried

0.051(0.007)

0.128(0.015)

0.073(0.013)

0.142(0.016)

Registered permanent

residence

$-0.054(0.015)$

$-0.168(0.008)$

$-0.084(0.002)$

$\underset{\star * \star *}{-0.193(0.014)}$

Work before retirement

\begin{tabular}{|c|c|c|c|c|}
\hline Formal job & $-0.073(0.007)$ & $-0.105(0.004)$ & $-0.065(0.009)$ & $-0.098(0.003)$ \\
\hline Informal job & $0.068(0.013)$ & $0.139(0.007)$ & $0.081(0.014)$ & $0.143(0.004)$ \\
\hline $\begin{array}{l}\text { Activities of daily living } \\
\triangle A D L \rrbracket\end{array}$ & $-0.057(0.015)$ & $-0.141(0.011)$ & $-0.100(0.015)$ & $\underset{\star \star \star \star}{0.158}(0.008)$ \\
\hline Mental state & $0.043(0.018)$ & $0.050(0.014)$ * & $0.008(0.013)$ & $0.037(0.013)$ \\
\hline \multicolumn{5}{|l|}{ Healthcare insurance } \\
\hline Resident Health insurance & $\underset{\star \star \star \star}{0.479}(0.024)$ & $\underset{\star \star}{0.281(0.017)}$ & $\underset{\star \star \star \star}{0.363(0.017)}$ & $0.244(0.020) * \star$ \\
\hline Employee health insurance & $\underset{\star}{0.342(0.019)}$ & $0.207(0.015)$ & $0.316(0.018)$ * & $0.209(0.014)$ \\
\hline Quality & & $0.038(0.021)$ * & & $0.034(0.015)$ * \\
\hline Accessibility & & $0.047(0.025)$ * & & $0.006(0.007)$ \\
\hline Diversity & & $\underset{\star \star *}{0.261(0.014)}$ & & $\underset{\star \star \star *}{0.240}(0.026)$ \\
\hline Rationality & & $\begin{array}{l}-0.060(0.019) \\
\star \star \star\end{array}$ & & $\frac{-0.062(0.008)}{* \star \star}$ \\
\hline Satisfaction & & & $0.180(0.016)$ & $0.113(0.014)$ \\
\hline Need & & & $\underset{\star \star \star \star}{0.059}(0.015)$ & $\underset{\star \star \star \star}{0.043(0.015)}$ \\
\hline Economic level & & & $-0.0011(0.001)$ & $-0.009(0.012)$ \\
\hline
\end{tabular}




\begin{tabular}{lllll} 
Family support & & & $0.076(0.008) * \star$ & $0.054(0.022)^{\star}$ \\
\hline Major illness & & & $0.133(0.011) * \star$ & $0.101(0.013) \star \star$ \\
\hline $\mathrm{F}$ & $1.70^{\star \star}$ & $12.16^{\star \star \star}$ & $4.63^{\star \star \star}$ & $11.52^{\star \star \star}$ \\
\hline Tolerance & $>0.106210$ & $>0.104704$ & $>0.105766$ & $>0.104280$ \\
\hline Adjusted $\mathrm{R}^{2}$ & 0.0166 & 0.2502 & 0.1023 & 0.2822 \\
\hline $\begin{array}{l}\text { Effective sample size } \\
\text { (person) }\end{array}$ & 670 & 670 & 670 & 670 \\
\hline
\end{tabular}

Note: (1) ${ }^{\star * \star}$ means significant at the $1 \%$ level, ** means significant at the $5 \%$ level, and * means significant at the $10 \%$ level. (2) Tolerance is a test of covariance of independent variables, and the tolerance of the above four models are all much larger than 0.10 , indicating that there is no serious covariance between the independent variables.

Model 1 incorporated only control variables, and the results showed that age $(b=0.008)$, Education $(b=0.07)$, and health insurance $(b=0.497)$ had a significant and positive correlation with the utilization of healthcare services for the older adults. Model 2 examined the impact of supply factors on the utilization of healthcare services for the older adults based on control variables, and the results showed that healthcare services quality $(b=0.038)$, service accessibility $(b=0.047)$, and service supply diversity $(b=0.261)$ had a significant and positive correlation with the utilization of healthcare services for the older adults, and service rationality $(b=-0.06)$ had a significant and negative correlation with, but service accessibility became no longer significant in the subsequent full model. This indicated that the better the service quality, the more likely the older adults would use the healthcare services; the more abundant and diverse the service supply, the more likely the older adults would use the healthcare services; the higher the healthcare services price, the less likely the older adults would use the service. This verifies the hypothesis 1 of this article: Supply factors, including: healthcare quality, accessibility, diversity, rationality had a significant correlation with the utilization of services for the older adults.

Model 3 examined the impact of demand factors on the utilization of healthcare services for older adults based on control variables, and the results showed that healthcare services satisfaction $(b=0.113)$, services need $(b=0.0043)$, family support $(b=0.054)$, and major illness $(b=0.101)$ had a significant and positive correlation with the utilization of healthcare services for the older adults. The impact of economic level $\mathbb{P}>0.1$ \was not significant, and the result remained robust in the subsequent full model 4. Result indicated that the more satisfied the older adults were with the service, the more likely they were to use the healthcare services; the greater the need for the healthcare services, the more likely they were to use the service; the greater the family support, the more likely they are to use the healthcare services; and the more illness the older adults were, the more likely they were to use the service. This verifies the hypothesis 2 of this article: Demand factors, including: healthcare satisfaction, need, economic level, family support, major illness had a significant correlation with the utilization of services for the older adults. 


\section{Difference between urban and rural areas in the utilization of healthcare services}

Because the household registration variables significantly impacted the healthcare services utilization of the older adults in the model 4 . Therefore, urban and rural older adults were discussed separately to explore the differences in the factors influencing healthcare services between urban and rural older adults, and Table 4 showed the regression results of healthcare services utilization for urban and rural older adults.

Table 4. Results of multiple regression analysis (urban-rural differences). 


\begin{tabular}{|c|c|c|}
\hline Variable & Model 5[Urban! & Model 6[Rural[ \\
\hline Age & $0.013(0.009) * *$ & $0.004(0.002)$ \\
\hline Gender & $-0.048(0.019)$ & $0.050(0.012)$ \\
\hline Education & $-0.022(0.014)$ & $0.058(0.014)$ \\
\hline \multicolumn{3}{|l|}{ Marriage } \\
\hline Married & $0.147(0.022)$ & $0.128(0.017)$ \\
\hline Unmarried & $0.225(0.025)$ & $0.151(0.018)$ \\
\hline \multicolumn{3}{|l|}{ Work before retirement } \\
\hline Formal job & $-0.200(0.018)$ & $0.654(0.025)$ * \\
\hline Informal job & $0.095(0.008)$ & $0.266(0.017)$ \\
\hline Activities of daily living $\triangle A D L \rrbracket$ & 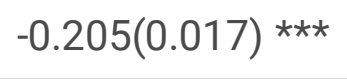 & $0.038(0.008)$ \\
\hline Mental state & $0.029(0.016)$ & $0.018(0.004)$ \\
\hline \multicolumn{3}{|l|}{ Healthcare insurance } \\
\hline Resident Health insurance & $0.279(0.020)$ & $0.354(0.017)$ * \\
\hline Employee health insurance & $0.338(0.021)$ & - \\
\hline Quality & $0.047(0.007)$ * & $-0.006(0.005)$ \\
\hline Accessibility & $0.032(0.006)$ & $-0.020(0.013)$ \\
\hline Diversity & 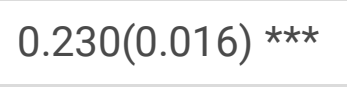 & $0.268(0.020) * \star \star$ \\
\hline Rationality & $-0.071(0.003) * *$ & $-0.029(0.011)$ \\
\hline Satisfaction & $0.136(0.014) * \star \star$ & $0.044(0.015)$ \\
\hline Need & $0.053(0.011) * \star \star$ & $0.023(0.014)$ \\
\hline Economic level & $-0.006(0.004)$ & $-0.042(0.07) * *$ \\
\hline Family support & $0.111(0.015) * *$ & $0.001(0.002)$ \\
\hline Major illness & $0.075(0.011)$ & $0.152(0.016)$ * \\
\hline$F$ & $8.77 \star \star \star *$ & 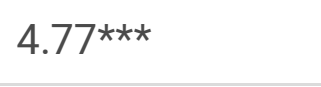 \\
\hline Tolerance & $>0.108678$ & $>0.195028$ \\
\hline Adjusted $\mathrm{R}^{2}$ & 0.3291 & 0.2316 \\
\hline Effective sample size (person) & 381 & 289 \\
\hline
\end{tabular}


Note: (1) *** means significant at the $1 \%$ level, ** means significant at the $5 \%$ level, and * means significant at the $10 \%$ level. (2) Tolerance is a test of covariance of independent variables, and the tolerance of the above two models are all much larger than 0.10 , indicating that there is no serious covariance between the independent variables.

The results were presented in Models 5 and 6 . For the urban older adults, unlike Model 4, the major medical illness $\triangle P>0.1$ in the demand factors were no longer significant. For the rural older adults, only healthcare services diversity $(b=0.268)$ and major illness $(b=0.152)$ had a significant and positive correlation with the utilization of healthcare services for the older adults. but the economic level $((b=-0.042)$ had a significant and negative correlation with the utilization of healthcare services for the older adults, the better the economic level of the older adults, the less likely they were to use community healthcare services. Models 5 and 6 verified hypothesis 3 : There were obviously differences in the utilization of healthcare services for the older adults between urban and rural areas.

\section{Oaxaca-Blinder decomposition analysis of medical service utilization factors among urban and rural older adults}

In order to understand the contribution of different factors to the difference in the utilization of healthcare services for the older adults in urban and rural areas, this article attempted to conduct Oaxaca-Blinder for the utilization of healthcare services for the older adults in urban and rural areas. Table 5 was the Oaxaca breakdown of the difference in outpatient expenditure between urban and rural areas.

Table 5. Oaxaca-Blinder decomposition of urban and rural medical services for the older adults. 


\section{Regression}

Coefficient

\begin{tabular}{|c|c|c|c|c|}
\hline \multirow{8}{*}{$\begin{array}{l}\text { Control } \\
\text { Variables }\end{array}$} & Age & -0.058 & 0.008 & -3.122 \\
\hline & Gender & 0.013 & 0.002 & 4.762 \\
\hline & Education & 0.004 & 0.003 & 0.893 \\
\hline & Marriage & 0.008 & 0.005 & 0.965 \\
\hline & Work & 0.007 & 0.004 & 0.917 \\
\hline & $A D L$ & -0.105 & 0.083 & -6.322 \\
\hline & Mental state & -0.082 & 0.067 & -4.396 \\
\hline & $\begin{array}{l}\text { Health } \\
\text { insurance }\end{array}$ & 0.257 & 0.095 & 16.862 \\
\hline \multirow[t]{4}{*}{ Supply Factors } & Quality & 0.112 & 0.094 & 5.125 \\
\hline & Accessibility & -0.089 & 0.824 & -5.882 \\
\hline & Diversity & 0.075 & 0.064 & 5.364 \\
\hline & Rationality & 0.132 & 0.872 & 8.082 \\
\hline \multirow{5}{*}{$\begin{array}{l}\text { Demand } \\
\text { Factors }\end{array}$} & Satisfaction & 0.092 & 0.091 & 6.454 \\
\hline & Need & 0.128 & 0.097 & 8.112 \\
\hline & Economic level & 0.086 & 0.019 & 6.321 \\
\hline & Family support & 0.147 & 0.087 & 8.061 \\
\hline & Major illness & -0.156 & 0.098 & -8.36 \\
\hline \multicolumn{2}{|l|}{ Feature Effect } & 0.012 & 0.104 & 0.169 \\
\hline \multicolumn{2}{|l|}{$\begin{array}{l}\text { Coefficient } \\
\text { Effect }\end{array}$} & 0.452 & 0.128 & 99.831 \\
\hline
\end{tabular}

Robust Standard Errors

Percentage

(\%)

$-3.122$ 
to the widening of the difference in medical service utilization factors. Health insurance explained $16.8 \%$ of the difference, which meant that when the level of medical insurance was the same in urban and rural areas, the factors affecting rural residents' medical service utilization increased accordingly, Age Gender Education Marriage Work ADL Mental state Health insurance and other factors explained a total of urban and rural The factors such as Age Gender Education Marriage Work ADL Mental state Health insurance explained $10.59 \%$ of the total expenditure difference between urban and rural areas.

Among the supply factors, quality of medical services explained $5.1 \%$ of the variance, accessibility explained $-5.8 \%$ of the variance, diversity explained $5.3 \%$ of the variance, and rationality explained $8.1 \%$ of the variance. Among the supply factors, service satisfaction explained $6.5 \%$ of the variance, service need explained $8.1 \%$ of the variance, economic level explained $6.3 \%$ of the variance, family support explained $8.1 \%$ of the variance, and major illness explained $-8.36 \%$ of the variance. Supply factors explained $12.8 \%$ of the variance for all explanatory variables. Demand factors all explanatory variables explained $20.6 \%$ of the variance. It could be concluded that controlling for other conditions being equal, there were more factors affecting healthcare utilization among urban older adults than rural older adults, and there was a significant phenomenon of health care utilization difference between urban and rural older adults.

\section{Discussion}

This article analyzes the factors influencing the utilization of health services for the older adults from both supply and demand factors and urban-rural differences through field research data, and three research hypotheses are verified. Based on the original Anderson model, the article analyzes the factors influencing health care utilization among the older adults from a supply and demand perspective. At last, we try to decompose the differences in the utilization of medical services for the older adults in urban and rural areas.

Among all the control variables, age is highly significant in models 1 to 5 , the older the older adults are, the more likely they are to use health services [41],it can be assumed that there is an "aging" tendency in the use of health services in China. At the same time, health insurance, as the biggest guarantee for the older adults to use health services in their later years, significantly influences the level of health service utilization, and the higher the level of health insurance, the more the older adults tend to use healthcare services, especially in the rural areas of China, due to the low income in rural areas, health insurance becomes the main reliance of the rural residents to use healthcare services. This is consistent with the expected hypothesis. [42] ADL has a significant and positive correlation with the utilization of healthcare services for the older adults. As the disease spectrum of Chinese residents continues to change, the incapacity of the older adults to take care of themselves due to chronic diseases and other diseases is becoming more prominent, and the less capable of taking care of themselves, the more willing they are to use healthcare services due to their objective needs. And since older adults in rural areas of China generally need to farm as well as farm work and are more capable of taking care of themselves, the ability of living self-care cannot significantly affect the healthcare services utilization of older adults for the rural older adults.

Page 18/25 
The results of the article show that the effect of economic level on the utilization of health services for the urban older adults was insignificant, this finding is contrary to previous studies on the utilization of social care services. The effect of economic level on the utilization of health services for the rural older adults was significant. On the one hand, China has built a nationwide medical insurance system, especially in urban areas, and medical insurance basically ensures that the health service needs of the older adults can be met. Since rural older adults with an annual income of less than 10,000 RMB account for more than $50 \%$ of the surveyed rural older adults people, the economic level is still a factor influencing their health service utilization due to their low savings and agricultural work in their later years.

The higher the quality of healthcare services supply, the greater the supply of healthcare services content, and the higher the reasonableness of service charges, the higher the level of healthcare services utilization of the older adults. Older adults people living in urban areas prefer service quality and reasonableness of service charges, while rural older adults people preferred diversity of healthcare supply. The accessibility of healthcare services has not significantly affect the utilization of healthcare services for the older adults, which is due to the fact that with the construction of urban and rural road networks, the overall transportation level is more convenient, and healthcare services can be accessed quickly and easily in both rural and urban areas, so with the development of social economy, accessibility does not affect the utilization of healthcare services for the older adults.

The results of the article show that the higher the acceptance of healthcare services by the older adults, the more satisfied the services, the greater the need for services, and the greater the possibility of their use of services. The higher the level of family support, the more older adults people prefer to use healthcare services [43]. The older adults with more illness prefer to use healthcare and healthcare services. The healthcare services need factors are further divided into urban and rural areas. The results show that among the urban older adults, those in need of healthcare services account for $64 \%$ of the surveyed urban older adults, and among the rural older adults, those in need of services account for the surveyed rural older adults. $58 \%$ of the population, it can be seen that the healthcare needs of the rural older adults are almost the same as the urban older adults, and the healthcare needs of the rural older adults may increase explosively in the future [44]. The influence of economic level among the demand factors is not significant, but it is a negative influence. To a certain extent, the higher the economic level of the older adults, the more likely they are to choose professional market-oriented services.

\section{Conclusion}

From the perspective of supply and demand, this paper constructs an analytical framework of the determinants of healthcare services for the older adults from a new perspective. Based on the analysis framework and from the perspective of supply and demand of healthcare services utilization, the differences between urban and rural areas in the utilization of medical care for the older adults and the influencing factors are studied. It provides a new research perspective to explore the influencing factors of healthcare services utilization for the older adults. 
This article compares and analyzes the factors that differentiate urban and rural older adults in healthcare utilization based on the supply and demand of healthcare services for older adults and analyzes the causes of potential differences and making feasible recommendations to improve health service utilization among the older adults. The main findings are as follows: age, health insurance, and ability to care for oneself in life (ADL) have a significant correlation with the utilization of healthcare services for the older adults. Supply factors and demand factors have a significant correlation with the utilization of healthcare services for the older adults. There are also significant differences in the factors influencing the utilization of health services by urban and rural older adults.

The main recommendations are as follows. When strengthening and improving the supply of healthcare services for the older adults, the previous thinking of "top-down" and "service-centered" should be changed, and gradually transformed into "bottom-up" and "demand-centered". When carrying out the content of healthcare and health services, do a good job of demand investigation and assessment, and strive to provide services from the perspective of the actual needs of the older adults, and improve the efficiency of service utilization. Second, the supply of healthcare services should be differentiated between urban and rural areas. The supply of healthcare services for the older adults in urban areas is in place, so we should focus on the professionalization of service supply, from "available" to "excellent"; healthcare services for the older adults in rural areas are lacking, and the healthcare needs of the older adults in rural areas may increase explosively in the future. Therefore, attention should be paid to the quantity of service supply, that is, from "none" to "with". At the same time, service accessibility is also an important factor affecting the utilization of rural older adults healthcare services. Finally, we should improve the subsidy system and expand the scope of services purchased by the government. On the one hand, for some older adults with low income and insufficient ability to pay, reasonable subsidies should be set according to their health and income levels, so that low-income older adults can also use medical and healthcare services; on the other hand, the scope of government purchased services should be expanded to include medical and healthcare services, so as to improve the utilization rate of services.

The limitations of the article are as follows. The article is limited by data limitations and only focuses on the factors affecting the utilization of healthcare and healthcare services in Shaanxi Province, which lacks typicality. The second is that the inclusion of explanatory variables is insufficient and the explanatory power of the model is not high. Future research can work in two ways: (1) Further expand the scope of research, field surveys in the developed eastern regions, verify and enrich existing research; (2) In the selection of indicators for the utilization of healthcare services for the older adults, more detailed measures will be adopted in the future. Interviews and surveys, continuous adjustment and improvement of indicators, provide a theoretical basis for enriching the analysis framework of the utilization of healthcare and health services for the older adults.

\section{Declarations}

\section{Acknowledgments}


Thanks to the survey group of Xi'an Jiaotong University for the help in data collecting. Any student participating in the survey can use the data for research.

\section{Author Contributions}

All authors participated in the questionnaire survey. C.Z., S.F. completed the overall design of the structure of the article. C.Z. and Q.N. reviewed the previous research results and made a literature review of the paper. The data were analyzed by C.Z., Q. N. C.Z. drafted the manuscript. C.Z., S.F. was involved in supervising the revision and quality of the manuscript. All authors have read and agreed to the published version of the manuscript. All authors have read and agreed to the published version of the manuscript. All authors have read and agreed to the published version of the manuscript.

\section{Funding}

This study was funded by the Major Projects of Philosophy and Social Science Research of the Ministry of Education (18JZD045)

\section{Availability of data}

The data used in this study can be obtained from the corresponding author if reasonably requested.

Additional files

Additional file 1. Fig.1 Hypothesised model to be tested. This study constructed an analytical framework for the impact of supply and demand on older adults healthcare services, as shown in Figure 1.

\section{Ethics approval and consent to participate}

This study is approved by the Department of Social Sciences of the Ministry of Education, PRC and the Medical Ethics Committee of Health Science Center of Xi 'an Jiaotong University (Approval Number20181200). These data do not involve any personal privacy information and are only used for research purposes. The respondents' filling in the questionnaire is regarded as informed consent.

\section{Consent for publication}

Not applicable.

\section{Competing interests}

The authors declare that they have no competing interests.

\section{References}

1. Marten R, Mclntyre D, Travassos C, Shishkin S, Longde W, Reddy S, Vega J. An assessment of progress towards universal health coverage in Brazil, Russia, India, China, and South Africa (BRICS). 
The Lancet.2014.9960(384):2164-2171.DOI: 10.1016 / S0140-6736(14)60075-1.

2. Zhou M, Wang H, Zeng X, Yin P, Liang XF. Mortality, morbidity, and risk factors in china and its provinces, 1990-2017: a systematic analysis for the global burden of disease study 2017 . The Lancet.2019,394(10204), 1145-1158.10.1016/S0140-6736(19)30427-1.

3. Thorslund M, Bergmark A, Parker MG. Difficult decisions on care and services for older adults people: the dilemma of setting priorities in the welfare state. International Journal of Social Welfare. 2010;6(3):197-206. DOI:10.1111/j.1468-2397.1997.tb00189.x.

4. Xu XL, Chen F, Tan HW. Comparison of health services accessibility between urban and rural among the elderly over 65 years old in chongqing, china. Journal of the American Geriatrics Society.2015,63(S2). DOI:10.1111/jgs.13704.

5. Zhang XF, Yu B, He, TT;Wang,PG. Status and determinants of health services utilization among older adults migrants in China. Global Health Research Policy. 2018;3(1):8. DOI:10.1186/s41256-0180064-0.

6. Wang Y, Wang J, Maitland E, Zhao Y, Ncholas S, Lu M. Growing old before growing rich: inequality in health service utilization among the mid-aged and older adults in Gansu and Zhejiang Provinces, China. Bmc Health Services Research. 2012, 12. DOI:10.1186/1472-6963-12-302.

7. Khan $\mathrm{MMH}$, Gruebner O, Kraemer. A.Fequently used healthcare services in urban slums of Dhaka and adjacent rural areas and their determinants. J Public Health. 2012(2):261-71. DOI:10.1093/pubmed/fdr108.

8. Andersen RM. Revisiting the behavioral model and access to healthcare care: Does it matter? Journal of Health Social Behavior. 1995;36(1):1-10. DOI:10.1093/pubmed/fdr108.

9. Han KM, Ko YH, Yoon HK, Han C, Ham BJ, Kim YK. Relationship of depression, chronic disease, selfrated health, and gender with health care utilization among community-living older adults. Journal of Affective Disorders.2018.DOI: 10.1016/j.jad.2018.08.044.

10. Ren JJ, Ding D, Wu QH, Liu CJ, Hao YH, Cui Y, Sun H, Ning N, Li Y, Kang Z, Shan LH, Zhao MM, Liu $\mathrm{BH}$. Financial Affordability, Health Insurance, and Use of Health Care Services by the Older adults: Findings From the China Health and Retirement Longitudinal Study. Asia Pacific Journal of Public Health,2019,31(6). DOI: 10.1177/1010539519877054.

11. Nowossadeck E. Impact of Population Aging on Utilization of Healthcare Rehabilitation in Germany Till 2040. Rehabilitation.2019,58(2).

12. Xu MR, Cheng ML, Gao XL, Wu HJ, Ding M, Zhang CZ, Wang X, Feng XP, Tai BJ, Hu DY, Lin HC, Wang B, Wang CX, Zheng SG, Liu XN, Rong WS, Wang WJ, Xu T, Si Y. Factors associated with oral health service utilization among adults and older adults in China, 2015-2016. Community dentistry and oral epidemiology.2020,48(1). DOI: 10.1111/cdoe.12497.

13. Wen XT, Cui LY, Yuan F, Liu XJ, Ouyang MF, Sun YX, Liu YC, Liu Y, Yu HQ, Zheng HL, Lu YA, Yuan ZK. Study on the Utilization of Inpatient Services for Middle-Aged and Older adults Rural Females in Less Developed Regions of China. International Journal of Environmental Research Public Health.2020,17(2). DOI:10.3390/ijerph17020514. 
14. Lu H, Wang W, Xu L, Li Z, Ding Y, Zhang J, Yan F. Healthcare seeking behaviour among Chinese older adults. International Journal of Health Care Quality Assurance. 2017;30(3):248-59.

DOI:10.1108/IJHCQA-10-2015-0132.

15. Chen C, Song J, Xu X, Zhou L, Wang Y, Chen H. Analysis of influencing factors of economic burden and healthcare service utilization of diabetic patients in China. PloS one.2020,15(10) DOI: 10.1371/journal.pone.0239844.

16. Evans, R.G.; Stoddart, G.L. Producing health, consuming health care. Social Science\& Medicine.1990,31(12), 1347-1363. DOI: 10.1016/0277-9536(90)90074-3.

17. Atake EH. Does the type of health insurance enrollment affect provider choice, utilization and health care expenditures? BMC Health Services Research.2020,20(1). DOI:10.1186/s12913-020-05862-7.

18. Jang Y, Kim G, Chiriboga DA. Health, healthcare utilization, and satisfaction with service: barriers and facilitators for older Korean Americans. J Am Geriatr Soc. 2010;53(9):1613-7. DOI:10.1111/j.15325415.2005.53518.x.

19. Burton RA, Zuckerman S, Haber SG, Keyes V. Patient-Centered Healthcare Home Activities Associated With Low Medicare Spending and Utilization. Annals of family medicine.2020, 18 (6). DOI: 10.1370/afm.2589.

20. Caner A, Cilasun SM. Health Care Services and the Older adults: Utilization and Satisfaction in the Aftermath of the Turkish Health Transformation Program. Gerontology and Geriatric Medicine.2019,5. DOI: 10.1177/2333721418822868.

21. Chan KY, Chiu HY, Yap DYH, Li CW, Yip T, Tsang KW, Tam WO, Au HY, Wong CY, Chan ML, Sham MK. Impact of structured advance care planning program on patients' wish items and healthcare utilization. Annals of palliative medicine.2020. DOI: 10.21037/apm-20-589.

22. Nelms L, Johnson V, Teshuva K, Foreman P, Stanley J. Social and Health Factors Affecting Community Service Use by Vulnerable Older People. Australian Social Work. 2009;62(4):507-24. DOI:10.1080/03124070903312823.

23. Wang Y, Wang J, Maitland E, Zhao YH, Nicholas S, Lu MS. Growing old before growing rich: inequality in health service utilization among the mid-aged and older adults in Gansu and Zhejiang Provinces, China. Bmc Health Services Research.2012, 12. DOI:10.1186/1472-6963-12-302.

24. Lartey ST, de Graaff B, Magnussen CG, Boateng GO, Aikins M, Minicuci N, Kowal P, Si L, Palmer AJ. Health service utilization and direct healthcare costs associated with obesity in older adult population in Ghana. Health Policy Plann. 2020;35(2):199-209. DOl:10.1093/heapol/czz147.

25. Hamada S, Takahashi H, Sokoto N, Jeon B, Mori T, lijima K, Yoshie S, Ishizaki T, Tamiya N. Household Income Relationship With Health Services Utilization and Healthcare Expenditures in People Aged 75 Years or Older in Japan: A Population-Based Study Using Healthcare and Long-term Care Insurance Claims Data. Journal of epidemiology.2019,29(10). DOI: 10.2188/jea.JE20180055.

26. Li JW, Hsieh HM, Weng SF, Lee IC. Polypharmacy and Utilization of Health Care Services: A Cohort Study of People Aged Over 50 Years in Taiwan. Asia Pacific Journal of Public Health.2019,31(3). DOI: $10.1177 / 1010539519828077$. 
27. Gordon SC, Fraysse J, Li S, Ozbay AB, Wong RJ. Disease Severity Is Associated With Higher Healthcare Utilization in Nonalcoholic Steatohepatitis Medicare Patients. The American journal of gastroenterology.2020,115(4). DOI:10.14309/ajg.0000000000000484.

28. Yonatan-Leus R, Strauss AY, Cooper-Kazaz R. Psychodynamic psychotherapy is associated with sustained reduction in health care utilization and cost. CLINICAL PSYCHOLOGY \& PSYCHOTHERAPY; 2020. DOI:10.1002/cpp.2527.

29. Shen M, He W, Yeoh E-K, Wu Y. The association between an increased reimbursement cap for chronic disease coverage and healthcare utilization in China: an interrupted time series study. Health policy and planning.2020,35(8):1029-1038. DOI: 10.1093/heapol/czaa087.

30. Komulainen K, Gluschkoff K, Garcia Velazquez R, Airaksinen J, Szmulewicz A, Jokela M. Association of depressive symptoms with health care utilization in older adults: Longitudinal evidence from the Survey of Health, Aging, and Retirement in Europe. International journal of geriatric psychiatry.2020. DOI: $10.1002 / g p s .5447$.

31. Safstrom E, Jaarsma T, Stromberg A. Continuity and utilization of health and community care in older adults patients with heart failure before and after hospitalization. Emma Säfström;Tiny Jaarsma;Anna Strömberg.2018,18(1). DOI: 10.1186/s12877-018-0861-9.

32. Chen $\mathrm{C}$, Song J, Xu X, Zhou L, Wang Y, Chen H. Analysis of influencing factors of economic burden and healthcare service utilization of diabetic patients in China. PloS one.2020,15(10) DOI: $10.1371 /$ journal.pone.0239844.

33. Guo M, Steinberg NS, Dong XQ, Tiwari A. Is family relations related to health service utilisation among older immigrants: Evidence from Chinese older adults in the United States. Health \& Social Care in the Community.2019,27(1). DOI: 10.1111/hsc.12642.

34. Downer B, Al Snih S, Raji M, Chou L-N, Kuo Y-F, Markides KS, Ottenbacher KJ. Healthcare utilization of Mexican-American Medicare beneficiaries with and without Alzheimer's disease and related dementias. PLOS ONE.2020,15(1). DOI: 10.1371/journal.pone.0227681.

35. Sum G, Ishida M, Koh GCH, Singh A, Oldenburg B, Lee JT. Implications of multimorbidity on healthcare utilisation and work productivity by socioeconomic groups: Cross-sectional analyses of Australia and Japan. PloS one.2020,15(4). DOI: 10.1371/journal.pone.0232281.

36. Chen Y, Yin Z, Xie Q. Suggestions to ameliorate the inequity in urban/rural allocation of healthcare resources in china. International Journal for Equity in Health. 2014,13. DOI:10.1186/1475-9276-1334.

37. Guo C, Li N, Chen G, Zheng XY. Mental health service utilization and its associated social factors among older adults people with a mental disability in China: A national population-based survey. Scand J Public Health.2019,47(2). DOI:10.1177/1403494817722705.

38. Quashie NT, Pothisiri W. Rural-urban gaps in health care utilization among older Thais: The role of family support. Archives of Gerontology and Geriatrics.2019,81. DOI: 10.1016/j.archger.2018.12.011.

39. Ko M-C, Lien H-Y, Woung L-C, Chen C-Y, Chen Y-L, Chen C-C. Difference in frequency and outcome of geriatric emergency department utilization between urban and rural areas. Jounal of the Chinese 
Healthcare Association.2019,82(4):282-288.DOI: 10.1097/JCMA.0000000000000053.

40. Han JQ, Meng YY. Institutional differences and geographical disparity: the impact of healthcare insurance on the equity of health services utilization by the floating older adults population evidence from China. International Journal for Equity in Health.2019,18. DOI: 10.1186/s12939-0190998-y.

41. Garcia-Ramirez J, Nikoloski Z, Mossialos E. Inequality in healthcare use among older people in Colombia. International journal for equity in health.2020,19(1).DOI: 10.1186/s12939-020-01241-0.

42. 45.Lu H, Wang W, Xu L, Li ZH, Ding Y, Zhang J, Yan F. Healthcare seeking behaviour among Chinese older adults. International journal of health care quality assurance.2017,30(3). DOI: 10.1108/IJHCQA10-2015-0132.

43. Wilson R. Moving Beyond Marriage: Healthcare and the Social Safety Net for Families. Journal of Law Medicine \& Ethics.2018,46(3):636-643. DOI: 10.1177/1073110518804217.

44. Choi Y, Nam K, Kim C-Y. Association Between Convenience of Transportation and Unmet Healthcare Needs of Rural Older adults in Korea. Journal of preventive medicine and public health.2019,52(6):355-365. DOI: 10.3961/.jpmph.19.172.

\section{Figures}

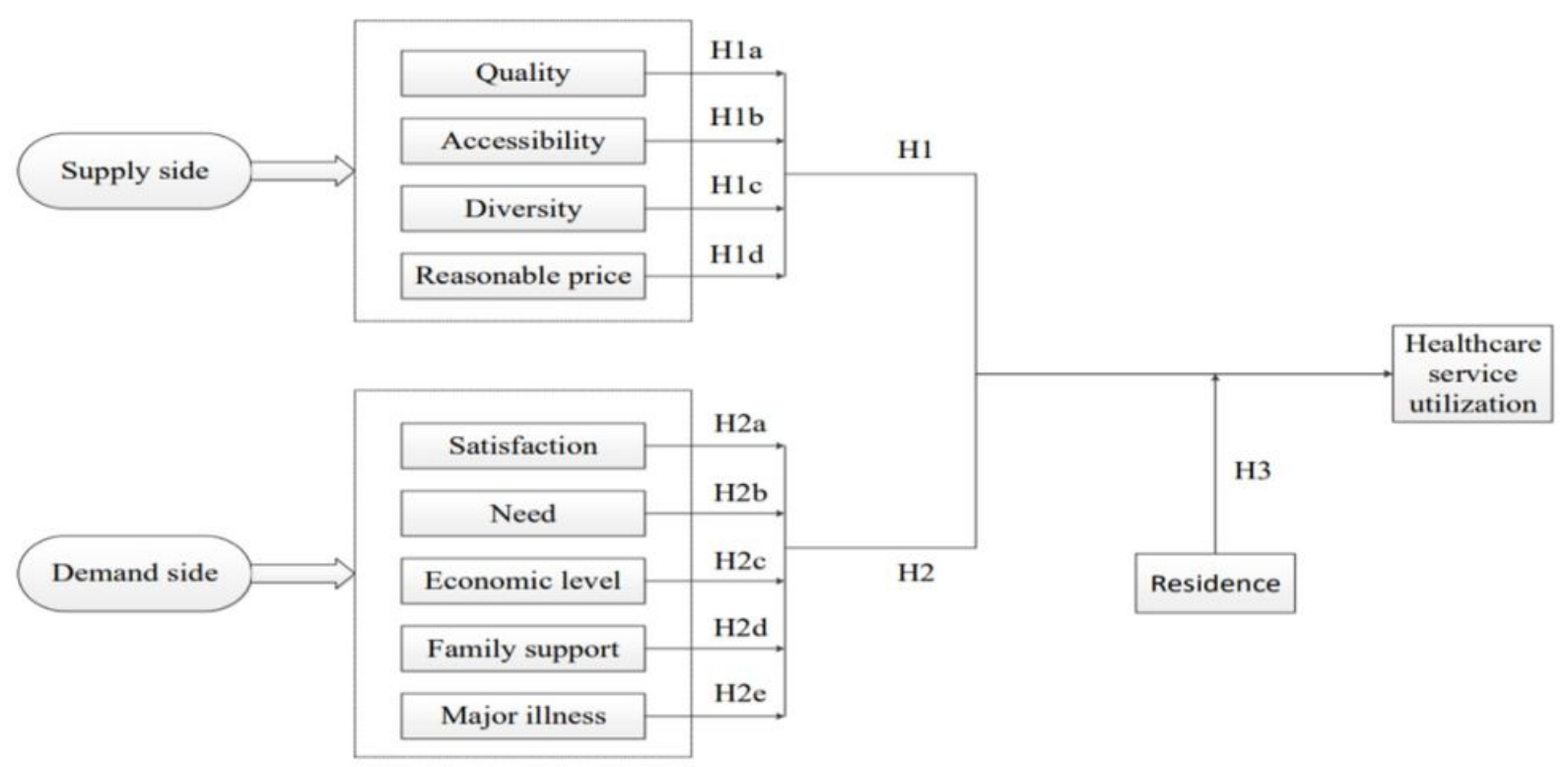

\section{Figure 1}

Hypothesised model to be tested 